\title{
Os desafios em utilizar a impressão 3D no processo ensino-aprendizagem de design
}

Natal Anacleto Chicca Junior, Instituto UFC Virtual - UFC - natal@virtual.ufc.br Leonardo Gomez Castillo, Design, CAC - UFPE - leonardo.a.gomez@gmail.com

Resumo: No segundo semestre de 2016, foi oferecida uma disciplina de prototipagem digital para os alunos de graduação do curso de Bacharelado em Design no Centro de Artes e Comunicação da Universidade Federal de Pernambuco. Ela foi realizada como parte da pesquisa de doutoramento sobre a integração da impressora 3D no processo ensino-aprendizagem da prática projetual de design. A proposta da disciplina foi analisar e apontar as dificuldades em relação à utilização da prototipagem digital, através de impressoras 3D open source, e como o uso desta ferramenta se comporta ao ser empregada no ensino do processo projetual. O presente artigo se propõe a apresentar e discutir os resultados desta disciplina.

Palavras-Chaves: Impressão 3D. Processo projetual. Ensino de design.

\section{The challenges of using 3D printing in the teaching-learning design process}

\begin{abstract}
In the second half of 2016, a digital prototyping course was offered to undergraduate students of the Bachelor of Design course at the Arts and Communication Center of the Federal University of Pernambuco. It was held as part of the PhD research on $3 \mathrm{D}$ printer integration in the teaching-learning process of the design practice. The purpose of the course was to analyze and point out the difficulties in the use of digital prototyping through open source 3D printers and how the use of this tool behaves when used in the teaching of the design process. The present paper proposes to present and discuss the results of this course.
\end{abstract}

Keywords: 3D printing. Design process. Design teaching.

\section{Introdução}

A tecnologia evolui a cada dia, em uma grande velocidade. Em meio a tantos avanços, Milincu \& Feier (2015) explicam que a indústria está passando por um processo de transformação e, para que os designers tenham a chance de ter sucesso no novo ambiente, é necessário que eles desenvolvam um novo conjunto de habilidades, concentrado especialmente na interface entre os ambientes reais e digitais. No 
desenvolvimento de projetos, essa interface se dá por meio dos protótipos que, segundo Alcoforado Neto (2014), permitem ao designer compreender, explorar, comunicar e avaliar as alternativas geradas. No entanto, o uso do protótipo é, geralmente, deixado para as fases finais do desenvolvimento do projeto, o que pode limitar o designer e demais atores do processo de design na avaliação de aspectos como: usabilidade, funcionalidade e estética. Tais dificuldades reforçam a necessidade de mudanças no processo e, por consequência, estimulam possíveis intervenções utilizando os avanços trazidos pelas ferramentas tecnológicas.

O uso cada vez mais intenso do computador foi um dos responsáveis por substituir os artefatos físicos pelos digitais no processo de representação. Contudo, as técnicas de prototipagem digital, segundo Tramontano \& Pereira Junior (2015), estão sendo responsáveis por trazer de volta o modelo físico ao centro desse processo. Nos últimos anos, de acordo com Junk \& Matt (2015), diferentes processos utilizando a impressão 3D oferecem a possibilidade de realizar testes de protótipos utilizando, diretamente, as alternativas virtuais geradas no computador e materializadas em modelos físicos. Em outras palavras, permite criar modelos híbridos reunindo algumas características de análise dos modelos físicos com os recursos digitais dos modelos virtuais. A vantagem em materializar um produto, através da impressora 3D, é a capacidade em prever erros, ainda na etapa de concepção, que talvez não tenham sido identificados na tela do computador ou na superfície do papel. Barbosa (2009) explica que os modelos, que antes eram apenas visualizados através de representações bidimensionais (seja na tela ou no papel), agora podem ser interagidos, estudados e avaliados, pois a prototipagem digital reproduz as formas do objeto com grande fidelidade dimensional. A produção de modelos físicos, através da impressão 3D, de acordo com Tramontano \& Pereira Junior (2015), permite que os elementos representados sejam facilmente alterados, redesenhados e gerem novos modelos físicos que, por sua vez, possibilitem novas verificações e alterações. O que se alinha com os conceitos de Baxter (2000) sobre a essência do processo de design se concentrar em três atividades: projetar, construir e avaliar, nas quais o protótipo é peça fundamental do processo iterativo.

Para Rivera-Chang (2015) é importante que os alunos se acostumem a construir variados tipos de modelos para a verificação e validação das soluções geradas, passando por todas as etapas do processo de projeto, até a sua aprovação. Pois mesmo parecendo ser penoso e frustrante para os alunos, principalmente quando o protótipo é rejeitado, é importante para compreender as características inerentes da atividade projetual. $\mathrm{O}$ 
aprimoramento através do conceito de aprender fazendo é, segundo Sass \& Oxman (2006), uma das principais características da prototipagem digital. Assim como, o processo de corrigir e refazer com base no conhecimento adquirido, a partir de artefatos anteriores, é um atributo importante da aprendizagem no design.

Lemke et al. (2016) afirmam que a impressão 3D tem se tornado, na área acadêmica, uma opção acessível para a produção de objetos físicos que podem ser utilizados como objetos de aprendizagem em diversas áreas e em vários níveis de ensino. Junk \& Matt (2015) e Rivera-Chang (2015), por exemplo, trazem pesquisas, nas quais, a impressora 3D vem auxiliando os alunos a produzirem melhores resultados, nas etapas de testes, ao utilizar protótipos, durante a fase de desenvolvimento de projetos de design.

De acordo com Barbosa (2009), não basta somente introduzir novas tecnologias na área de design, é preciso avaliar os impactos e como utilizá-las de maneira adequada. Buscando avaliar o impacto das novas tecnologias na área de design, no segundo semestre de 2016, foi oferecida uma disciplina de prototipagem digital para os alunos de graduação do curso de Bacharelado em Design no Centro de Artes e Comunicação da Universidade Federal de Pernambuco. A proposta da disciplina foi analisar e apontar as dificuldades em relação à utilização da prototipagem digital, através de impressoras $3 \mathrm{D}$, e como o uso desta ferramenta se comporta ao ser empregada no ensino do processo projetual. A pesquisa não visa apenas conhecer, mas também desmistificar a ferramenta de impressão 3D e testar na prática o seu potencial, vantagens e limitações ao trazer essa tecnologia para dentro das salas de aula. Entre os resultados apresentados, estão os relatos das experiências e das atividades realizadas na disciplina de projeto, ao materializar os arquivos digitais em objetos físicos em um processo cíclico de retroalimentação, na tentativa de ampliar as análises dos aspectos formais dos artefatos produzidos. Este artigo se propõe a apresentar e discutir os resultados desta disciplina.

\section{Estrutura e ferramentas de avaliação da disciplina}

A disciplina apresentada neste artigo fez parte de uma pesquisa de doutoramento sobre a integração da impressora 3D (síntese aditiva por filamento) no processo ensinoaprendizagem da prática projetual de design. Sendo assim, ela se utilizou de pesquisas prévias sobre o estado da arte, assim como das observações e dos resultados de experiências realizadas anteriormente, conforme descrito em Chicca Junior (2017). A sua estrutura foi planejada a partir de três atividades com níveis de dificuldade crescentes: a primeira, com caráter mais introdutório, se preocupou em apresentar os fundamentos da 
impressão 3D e mostrar o potencial da materialização de formas complexas; a segunda buscou explorar um pouco mais o uso da ferramenta ao trabalhar, além da impressão e escaneamento 3D, diferentes meios de representação para o estudo da forma, compreendendo o potencial de cada um deles e aprendendo qual seria mais indicado para cada etapa do projeto e até mesmo combiná-los, caso fosse necessário; por fim, a terceira e última atividade se propôs a combinar todo o conteúdo visto na disciplina, acrescido da modelagem paramétrica para o desenvolvimento de órteses. O uso da modelagem paramétrica foi pensado para o ajuste de moldes padronizados de órteses com o objetivo de atender diferentes partes do corpo de qualquer pessoa, a partir de algumas medidas do paciente.

O método de ensino adotado com o objetivo de que os alunos compreendam os conceitos através da própria execução de projetos e, com isso, apesar de contar com uma introdução teórica em algumas aulas, a disciplina foi caracterizada, em boa parte de seu conteúdo, por atividades práticas. Durante as aulas, os professores utilizaram o modelo guia, acompanhando de perto o progresso de cada aluno ao longo das atividades, auxiliando com possíveis dúvidas e/ ou dificuldades, mas ao mesmo tempo proporcionando uma maior liberdade aos alunos para desenvolverem os seus projetos.

Como o objetivo da pesquisa requer o estudo da impressão 3D no ensino de design, umas das preocupações foi, justamente, poder verificar na prática os benefícios e os impedimentos da inserção da ferramenta em disciplinas projetuais, avaliar o seu desempenho durante as aulas e como ela se comporta em um cenário real de uma disciplina. Para isso, de forma a avaliar os alunos, através de recursos mais científicos e embasados do que simplesmente a abordagem empírica, ao final de cada uma das três etapas, foram aplicados questionários de avaliação da disciplina.

Foram aplicados três diferentes modelos de questionários para cada etapa da disciplina. Os questionários foram compostos por questões de múltiplas escolhas e também dissertativas. Em cada etapa, foram aplicados os mesmos modelos de questionários, para cada aluno, de forma a facilitar a coleta e análise dos dados. Além de avaliar o desempenho e dificuldades em cada uma das atividades, eles também verificaram as expectativas em relação às aulas e as pretensões em continuar utilizando a impressão 3D para os projetos acadêmicos e profissionais. Os resultados dos três modelos de questionários aplicados aos alunos foram cruzados com observações e análises prévias, realizadas ao longo da disciplina, com o objetivo de validar as informações e até mesmo 
obter novos dados que poderão promover estudos futuros. Parte destes resultados serão apresentados a seguir através das descrições de suas informações.

\section{Resultados e discussões}

Segundo os questionários aplicados, uma das maiores dificuldades apontada pelos alunos, em todas as três atividades, foi relacionada ao uso dos softwares de modelagem 3D. Ao longo da disciplina foram sugeridos alguns softwares que poderiam ajudar em cada tarefa. $\mathrm{Na}$ atividade 2, por exemplo, toda a turma foi incentivada a utilizar ao menos um software de modelagem orgânica por utilizar uma metáfora muito próxima ao processo de modelagem manual tradicional. Mas os alunos tiveram que aprender todos os softwares, exceto por uma breve oficina introdutória sobre modelagem paramétrica. Apesar da grande adesão de interessados no uso das ferramentas digitais, os alunos se sentiram frustrados por não ter domínio em sua utilização. Eles consideram responsabilidade da universidade ensinar a usar os softwares, mesmo que as disciplinas não possuam essa única finalidade.

Considerando que, os resultados do desempenho de cada uma das atividades são afetados pelo grau de habilidade na utilização dos softwares, é preciso encontrar maneiras de conseguir que os alunos busquem o aprendizado destas ferramentas. As estratégias adotadas tanto na experiência anterior, a qual foram desenvolvidas oficinas de alguns softwares específicos, quanto nesta disciplina, onde os alunos foram responsáveis em buscar todo o conhecimento necessário, não foram suficientes para suprir as demandas para as atividades propostas em sala de aula. Em ambas as disciplinas os alunos reclamaram a respeito da dificuldade em não saber utilizar os softwares. Logo, ainda não foi encontrada uma solução adequada para o nivelamento do conhecimento dos alunos em uma determinada ferramenta digital.

O uso da modelagem paramétrica, por exemplo, oferece diversas possibilidades para o processo projetual de design. Contudo, mesmo tendo contado com uma oficina voltada ao ensino de um software específico, foi muito difícil para os alunos dominarem o uso da ferramenta, ainda mais em um espaço de tempo tão restrito. Neste caso, acreditase que o ideal seja explorar a prática da modelagem paramétrica ao longo de toda a disciplina ou então com alunos que já saibam utilizar o software. Mas, apesar de todas as dificuldades, a combinação entre modelos digitais paramétricos e impressão 3D na atividade 3 mostrou grande potencial como recurso de inovação nos cursos de design. 
O desenho foi destacado como sendo o meio de representação com maior facilidade para os alunos exteriorizarem as suas ideias. Ao considerar o desenho a ferramenta de representação utilizada desde a infância, cria uma empatia mesmo com aqueles que não possuem muita habilidade no ato de desenhar. Em contrapartida, tanto a massa de modelar quanto o software 3D foram apontados como as ferramentas de maior dificuldade ao representar as ideias. Neste caso, a dificuldade em utilizar a massa de modelar demonstra que, mesmo tendo sido utilizada pelos alunos na infância (assim como o desenho), essa prática se perdeu com a falta de estímulo e ausência de oficinas e/ou ateliês, tanto na escola quanto nas universidades, para exercitar as práticas manuais de representação resultando no esquecimento desta habilidade.

Em relação ao uso da impressão 3D, foi interessante notar o entusiasmo dos alunos, mesmo depois do deslumbramento típico dos primeiros contatos, ao ver seus projetos sendo materializados. Eles ficaram espantados e admirados ao ver seus arquivos digitais ganhando forma física seguido de uma grande empolgação em poder manuseálos, logo após concluídos. Porém, apesar do início bastante positivo com os exercícios introdutórios da atividade 1 , o mesmo ritmo de uso de impressão 3D não conseguiu ser mantido nas atividades 2 e 3 , passando a utilizá-la apenas para gerar os modelos finais. $\mathrm{O}$ que, infelizmente, contradiz um dos principais objetivos da disciplina que era justamente estimular o uso da impressão 3D como ferramenta de retroalimentação no processo cíclico de geração de alternativas.

Os alunos demonstraram uma facilidade maior com os métodos tradicionais, mas não se sabe se é devido a falta de prática no uso da impressora $3 \mathrm{D}$ ou se ela realmente não é uma ferramenta adequada para a etapa de geração de alternativas. Dentre alguns dos fatores apontados pelos alunos nos questionários por não ter explorado mais o uso da impressora 3D estão: o tempo de espera para o modelo ficar pronto, a dificuldade em manusear o equipamento e a falta de acesso ao equipamento fora do horário de aula.

Em relação ao tempo de espera, ainda não foi encontrada uma solução ideal para o gerenciamento de impressão dos arquivos dos alunos dentro do horário de aula. Alguns modelos levavam mais de 2 horas para serem impressos individualmente, tornando inviável o processo de materialização de cada grupo durante o horário de aula. A solução mais simples (ou ao menos a mais imediata) de tentar contornar essa barreira é disponibilizar o uso do equipamento fora do horário de aula. Porém, isso acarreta em ter algum tipo de controle em relação ao acesso do laboratório e até mesmo um técnico para acompanhar o uso da impressora 3D caso ela apresente alguma falha. Além disso, 
trabalhar fora do horário de aula quebra o ritmo da execução das atividades e não permite que toda a turma tenha contato com o processo de impressão dos outros alunos.

O método que foi utilizado na disciplina se assemelha a um birô de serviços, sendo o professor responsável por materializar todos os arquivos digitais dos alunos fora do horário de aula e também por entregar todos os modelos prontos na semana seguinte. As falhas apontadas neste processo consistem tanto na falta de acompanhamento dos alunos no processo de impressão quanto no atraso gerado, já que para cada modelo físico que eles queiram gerar, o prazo acaba sendo de 1 semana (período entre uma aula e outra pois eram encontros semanais). Como grande parte dos modelos não eram impressos durante o horário de aula, não foi possível estabelecer a dinâmica do processo cíclico de gerar diversos artefatos físicos para estudos do objeto, seja para refinar ou validar a sua forma. Algumas soluções podem ser pensadas para tentar contornar isso, desde ajustes nos equipamentos ou nos arquivos para agilizar o processo, trabalhar melhor o conceito de baixa fidelidade dos protótipos para simplificar os modelos e acelerar as impressões durante a fase de ideação, analisar a possibilidade de uma carga horária diferenciada para as aulas que trabalhem com uma impressão mais detalhada dos modelos, ter um número maior de impressoras 3D disponíveis para a disciplina, entre outras. O que remete à necessidade de espaços adequados. Ou seja, nas disciplinas, cuja proposta é poder explorar o uso de ferramentas digitais em benefício do processo projetual, é preciso ter locais e equipamentos preparados para realizar os experimentos em sala de aula. Desta forma, contribuiu para o andamento correto do cronograma como também influencia diretamente no desempenho dos alunos em suas atividades. Vale destacar as dificuldades e desafios das universidades públicas em obter verbas para comprar e manter equipamentos e/ou insumos a fim de conseguir um mínimo de infraestrutura para oferecer cursos com disciplinas ligadas à área de tecnologia.

Mas, apesar da impressão 3D ter sido mais utilizada como recurso de apresentação do projeto já finalizado, foi possível identificar os alunos aplicando diferentes ferramentas de representação para os estudos do projeto e notar como cada grupo acabou adotando um método diferente para expressar visualmente suas ideias. A disciplina conseguiu integrar diferentes meios de representação em um mesmo exercício, em especial, na atividade 2, na qual os alunos utilizaram variadas técnicas e ferramentas na criação de seus projetos. Os modelos manuais em massa de modelar, por exemplo, serviram como base para os estudos de volumetria dos personagens. Deste modo, acredita-se que com uma habilidade maior no uso e mais velocidade no seu processo, a 
impressão 3D pode contribuir ao materializar modelos físicos para os estudos da forma durante as aulas de projeto. A partir de alguns ajustes e/ou melhores alternativas de ferramentas de escaneamento 3D, combinado com uma agilidade maior na impressão 3D dos modelos em sala de aula, se mostra como uma excelente oportunidade para os alunos trabalharem com diversos recursos no processo iterativo de representação, avaliação e validação de seus projetos. As ferramentas de escaneamento 3D foram mais aplicadas na atividade 3 do que na 2, reforçando que, graças a escala maior dos modelos a serem digitalizados, ferramentas tais como o Kinect proporcionam bom desempenho para esta função. Por fim, na terceira atividade os alunos utilizaram, por conta própria, diferentes meios de representação para cada etapa do projeto, mostrando que é possível instigar o caráter proativo dos alunos em buscar soluções, além de mudanças do raciocínio projetual, em utilizar protótipos físicos ao invés de contar apenas com os modelos digitais.

\section{Conclusões}

As evoluções tecnológicas estabeleceram os computadores no cotidiano das pessoas e foram responsáveis por trazer maior agilidade na execução de tarefas. Como consequência desta visão de maior eficiência, arquitetos e designers passaram a adotar o meio digital em detrimento das atividades manuais na execução de projetos. O que, por sua vez, levou tanto estudantes quanto profissionais a substituírem o desenho e modelagem manuais pelo digital. Os experimentos pedagógicos realizados puderam comprovar a preferência dos estudantes pelo computador frente aos métodos tradicionais de representação.

Mas, apesar da impressora 3D também estar relacionada ao uso de computadores, ela demonstra um rompimento na relação que o designer possui com o projeto. Através do processo de materialização de arquivos digitais em objetos físicos, ela vem se mostrando como uma ferramenta promissora para estudos da forma e volumetria que antes estavam limitadas a visualização bidimensional, através das telas dos computadores ou que demandaria bastante tempo e muita habilidade para ser desenvolvido através do processo de modelagem manual. O modelo físico permite retomar o processo de análise, avaliação e validação de determinadas fases do projeto a partir de estudos realizados pelo processo de materialização. Ao mesmo tempo, a impressão 3D também contribui na conscientização da necessidade em desenvolver modelos e protótipos ao longo das etapas de desenvolvimento em benefício do projeto. 
Contudo, mesmo com tantos benefícios, a ferramenta de impressão 3D ainda apresenta um perfil de uso bastante experimental, resultando em muitas falhas no processo de materialização, nível de dificuldade acentuado em configurar de maneira correta para obter os resultados desejados. O seu aprendizado ainda se dá pelo processo de tentativa e erro. Uma das suas maiores dificuldades, e que gera muita frustração em relação ao uso da ferramenta, é conseguir obter um resultado final do objeto físico próximo de seu arquivo digital de origem. A quantidade de configurações necessárias nos modelos mais acessíveis resulta em um grande nível de dificuldade em operá-la e conseguir bons resultados. Como se isso não bastasse, muitos dos equipamentos ainda requerem cuidados e certo domínio na sua manutenção já que eventualmente será necessário desmontar, montar, consertar e até mesmo trocar algumas peças. A falta de habilidade na manutenção dos equipamentos, a falta de recursos financeiros e a distância física das assistências técnicas podem ser grandes impeditivos ao querer adotar a impressão 3D no fluxo de trabalho das universidades públicas.

Além dos desafios em conhecer e dominar a ferramenta de impressão 3D, os experimentos pedagógicos demonstraram a dificuldade dos alunos em relação ao próprio processo projetual. A falta de experiência no desenvolvimento e aplicação de protótipos reforça, por exemplo, o aparecimento da prototipagem após o processo de avaliação e seleção de alternativas, ou seja, com a finalidade apenas de visualizar a solução de design escolhida. Outro ponto a ser destacado é a falta de diversificação de estudos por parte dos alunos ao longo de todo o projeto. Eles já se mostram satisfeitos logo com os primeiros resultados, com soluções pouco ousadas faltando esforço em pensar diferentes propostas ou até mesmo refinar as existentes. Mesmo assim, a prototipagem digital permite o aluno sair do campo teórico e poder construir a sua proposta de produto, o que ajuda a incentiválo no aperfeiçoamento do modelo. Este tipo de atividade contribui para aperfeiçoar a sua noção espacial e melhorar a sua capacidade de comunicação a partir do uso de protótipos nos projetos.

Por fim, apesar de todas as dificuldades enfrentadas ao longo da disciplina, os resultados dos questionários aplicados demonstraram um aumento do interesse dos alunos que pretendem continuar utilizando a impressão 3D, seja durante o curso ou na atividade profissional. Além disso, todos os alunos acreditam que a impressora 3D deve fazer parte do curso de design. Outro dado positivo foi que quase todos os alunos pretendem continuar utilizando a impressão 3D em seus projetos, seja na universidade ou fora dela. Logo, independente das experiências de cada aluno, ao longo da disciplina, toda a turma 
teve uma visão bastante positiva em relação ao uso da ferramenta de impressão 3D no processo projetual de design. Entretanto, os resultados dos questionários também mostraram que apesar do otimismo no uso da ferramenta, muitos alunos não têm uma ideia bem definida de como utilizar a impressão 3D. O que mostra a importância em reforçar iniciativas em conjunto entre laboratórios de pesquisa com as disciplinas acadêmicas para que ambos consigam estudar formas de explorar melhor o uso das ferramentas de prototipagem rápida aplicadas no ensino projetual.

\section{Referências}

ALCOFORADO NETO, M. G. Metodologia de Design Mediada por protótipos. Tese (Doutorado em Design). Universidade Estadual Paulista. Bauru, 2014.

BARBOSA, R. T. Design \& Prototipagem: Conhecimento e uso da prototipagem rápida no design brasileiro. Dissertação (Mestrado em Design). Universidade Estadual Paulista. Bauru, 2009.

BAXTER, M. Projeto do produto: Guia Prático para o desenvolvimento de novos produtos. São Paulo: Edgard Blucher, 2000.

CHICCA JUNIOR, N. A. A integração da impressora 3D FDM no processo ensinoaprendizagem da prática projetual de design. Tese (Doutorado em Design) Universidade Federal de Pernambuco. Recife, 2017.

JUNK, S.; MATT, R. New Approach to Introduction of 3D Digital Technologies in Design Education. In: Procedia. CIRP 36, 2015. p.35-40.

LEMKE, R.; SIPLE, I. Z; FIGUEIREDO, E. B. OAs para o ensino de cálculo: potencialidades de tecnologias 3D. In: Revista Novas Tecnologias na Educação (RENOTE). CINTED-UFRGS. Porto Alegre, v.14, n.1, julho, 2016.

MILINCU, C. O.; FEIER, I. Improving Industrial Design through Hands-on Experimentation. In: Procedia - Social and Behavioral Sciences. n.197, 2015. p.17961802.

RIVERA-CHANG, J. Case study: Use of online tools in the classroom and their impact on industrial design pedagogy. In: Procedia Manufacturing. n.3, 2015. p.2275-2280.

SASS, L.; OXMAN, R. Materializing design - the implications of rapid prototyping in digital design. In: Design Studies. v. 27, n. 3, p. 325-355. Maio, 2006.

TRAMONTANO, M.; PEREIRA JUNIOR, A. Ressignificando o modelo físico: impressão 3D e ensino de projeto de arquitetura. In: SIGRADI 2015. São Paulo: Blucher, 2015. p.350-354. 